\title{
Upper limb mobility and personal management in patients with stroke attending occupational therapy at a tertiary hospital in Gauteng
}

\author{
Zukiswa Msengana, BSc OT (UWC); MSc OT (Wits) http://orcid.org/0000-000 I-7302-8088 \\ Senior Occupational Therapist, Baragwanath Hospital, Johannesburg \\ Postgraduate student. Department of Occupational Therapy, School of Therapeutic Sciences, Faculty of Health Sciences, Univer- \\ sity of the Witwatersrand
}

Patricia De Witt, Nat. Dip. OT (Pretoria); MSc OT (Wits); PhD (Wits) http://orcid.org/0000-0003-36I 2-0920 Sessional Adj Professor, Department of Occupational Therapy, School of Therapeutic Sciences, Faculty of Health Sciences, University of the Witwatersrand

\author{
Antonette Owen, BOT (UP), MSc OT (Wits) http://orcid.org/0000-0002-4573-4 I 85 \\ Community Occupational Therapist, PRS Support Services, Sydney, New South Wales Australia. Lecturer, Department of \\ Occupational Therapy, School of Therapeutic Sciences, Faculty of Health Sciences, University of the Witwatersrand
}

Denise Franzsen, BSc OT (Wits), MSc OT (Wits), DHT (Pret) PhD (Wits) http://orcid.org/0000-000 I-8295-6329 Sessional Senior Lecturer, Department of Occupational Therapy, School of Therapeutic Sciences, Faculty of Health Sciences, University of the Witwatersrand

Introduction: This study described the outcomes for upper limb motor function after stroke and personal management of patients attending occupational therapy at a tertiary hospital in Gauteng, up to two months' post-discharge.

Methodology: A quantitative, descriptive correlation design used assessments of upper limb motor function and independence in personal management to collect the data. Forty-five participants received routine rehabilitation including occupational therapy at the hospital. The same measurements were administered on discharge and during out-patient follow up at one and two months.

Results: Results indicated that of 45 participants only 33 were available for reassessment at discharge. These participants had significant improvement in upper limb motor function and personal management. At discharge $48 \%$ of participants had $>80 \%$ recovery of upper limb function and $59 \%$ had achieved independence or modified independence in personal management. The correlation between upper limb function and $73 \%$ personal management at discharge was strong, indicating an association between return of upper limb function and independence in personal management. By two months post discharge the correlation between the variables was low, as while only $20 \%$ of the 15 participants who returned for therapy at month 2 were dependent for personal management and over $50 \%$ presented with no or poor upper limb function.

Discussion and Conclusion: Rehabilitation including occupational therapy intervention contributed to participant's improved performance in personal management tasks, even when upper limb motor function recovery was suboptimal. The intervention for personal management and compensatory techniques taught to participants resulted in independent or modified independence two months after discharge.

Key words: stroke; upper limb motor recovery; personal management

\section{INTRODUCTION}

The high annual incidence for stroke in South Africa is 75000 new cases per year, which creates an economic burden of care on an overburdened public health sector ${ }^{\prime}$. Consequently, the length of hospital stay for patients with stroke in South African public hospitals has been found to be shorter than in other countries ${ }^{2,3}$. This is the context in which occupational therapy services are provided at a large public hospital in Soweto, South Africa, where an average of 80 stroke survivors are referred for rehabilitation every month. A routine occupational therapy stroke protocol, which focusses on improving motor mobility and independence in all activities of daily living (ADL) is used to treat these patients. The programme offered to these stroke patients is constrained by the context of the hospital and the population it serves. The rehabilitation service is offered by a multi-disciplinary team in line with the South African Guideline for the Management of Ischaemic Stroke and Transient Ischaemic Attack ${ }^{4}$. Patients with stroke are assessed by an interdisciplinary rehabilitation team within 24 hours of admission, if possible, and communication is initiated with the patient and where possible their family ${ }^{5}$.

The stroke survivors are initially seen as inpatients for the duration of their short hospitalisation, reported to be between six and ten days in public hospitals in South Africa ${ }^{2,3}$. During this short stay limited time is available for occupational therapy to address impairments, teach compensatory $A D L$ techniques and educate patients as well as their families and carers about managing after discharge from hospital $\left.\right|^{6,7}$. Other rehabilitation interventions included physiotherapy and speech therapy and patients typically attend a minimum of three occupational therapy sessions per week as inpatients. Rehabilitation is a protracted process but after discharge from a public hospital the availability of and access to further outpatient rehabilitation is limited. Thus, in this study the patients were referred for follow-up occupational therapy after discharge from hospital on a monthly basis due to pressure 
on staff availability. This service is offered as research indicates continued rehabilitation after discharge during the first year after stroke reduces the risk of deterioration in function and improves daily living activities ${ }^{8}$. This was confirmed by Teasell et al. ${ }^{9}$ who found that even with infrequent outpatient therapy sessions on a monthly basis, there is high level evidence that these sessions in conjunction with home-based stroke rehabilitation programmes are effective in achieving modest gains in ADL following inpatient rehabilitation. However, the lack of home-based rehabilitation services in Soweto and the poor return of patients with stroke for outpatient care is of great concern ${ }^{3}$. Both of these factors affect the duration and intensity of the post discharge rehabilitation programme. The long-term gains in motor function described in the international literature from routine but more intense occupational therapy programmes, may also not be achieved in the majority of cases in this service delivery context ${ }^{10}$.

Since the occupational therapy programme at the hospital in which this study was based focusses on motor recovery and occupational performance for patients with stroke, the aim of the study is to determine the outcomes of upper limb functional movement and personal management as well as the correlation between these two variables on referral, at discharge and at two months' post discharge.

\section{LITERATURE REVIEW}

Literature indicates that a number of contextual factors affect the rehabilitation outcomes of stroke survivors. These include, amongst others the right time to start therapy post stroke, the length of hospital stay and access to outpatient rehabilitation. Current literature advocates that stroke survivors should receive rehabilitation that includes mobilisation and personal management retraining within 24 hours of the stroke incident regardless of the type of stroke $e^{4}$. However, the concept of the best time to start therapy post stroke is controversial. While Bernhardt et al. " as well as Craig et al. ${ }^{12}$ found no conclusive evidence that supported early mobilisation started within three days of the stroke. Rohweder et al. ${ }^{13}$ indicated that starting treatment within 24 hours after stroke had positive benefits in terms of successful functional outcomes at three months post stroke. They reported this was due to the prevention of complications caused by immobility in bed, which can be life threatening ${ }^{13}$ with high level evidence for frequent short duration out-of-bed sessions at this stage ${ }^{8}$.

Starting therapy soon after admission in South African public hospitals provides an the opportunity for stroke survivors to receive a few hours of therapy but this is usually nowhere near the 20 hours practice recommended for achieving independence in personal management activities ${ }^{14}$. The average hospital stay was seven days in a study in KwaZulu Natal and six in Gauteng ${ }^{2,15}$. In the Western Cape, the mean length of hospitalisation in the Western Cape was six to ten days and thus, at discharge, most patients were still dependent for many aspects of personal management ${ }^{3}$.

Compliance to outpatient follow up rehabilitation after discharge has been reported as poor for most patients with stroke attending public hospitals in South Africa. A lack of finances and access to transport was identified as a major barrier to accessing outpatient rehabilitation services ${ }^{16,17}$. Wegner and Rhoda ${ }^{18}$ found that that cultural factors affected compliance in rural communities in Kwa-Zulu Natal, where patients did not believe that rehabilitation would help them to recover.

A number of studies on patients with stroke indicate that demographic and medical factors also influence the outcomes for upper limb functional movement and personal management. While the severity of stroke including baseline neurological status, upper limb paresis and age were shown to have the most significant effect on personal management outcomes early after stroke, at discharge and at three months post stroke ${ }^{3,19}$. In another study Meijer et $\mathrm{al}^{20}$ also identified less common predictive factors such as dysphagia, ideomotor apraxia, ideational apraxia and visuo-spatial construction problems.
A prognostic factor for motor recovery of the upper limb is related to the initial amount of paresis at onset as well as the site of the lesion ${ }^{21}$. Lesions in the middle cerebral artery (MCA) and anterior cerebral arteries result in greater deficits in the motor function of the upper limb ${ }^{21}$. These findings supported those of Kwakkel et al. ${ }^{10}$ who found that upper limb movement can be predicted by observing lack of voluntary movement in the first week and lack of synergistic movements at week four post stroke, both of which result in poor motor outcomes at six months post stroke. In contrast, it has been identified that the size of lesion does not have much effect on motor recovery if the area of middle cerebral artery (MCA) distribution is not damaged ${ }^{22}$.

Most recent research findings investigating intensity of arm training in motor recovery post stroke revealed that when the amount of therapy was increased during the post-acute stage, there was a significant increase in functional mobility of the affected upper limb after six weeks and that recovery in motor function following stroke plateaued after a year ${ }^{23}$. Kwakkel et al. ${ }^{10}$ also reported a significant improvement in motor functioning after six weeks of intensive therapy early post stroke. They associated this with the neural reorganisation and optimal neural repair resulting in greater return of motor function in the first three to six months post stroke ${ }^{10}$. However, patients with poor motor outcomes may gain independence in personal management with the use of adaptive methods and by making use of one handed techniques ${ }^{24}$ thus, they should also be taught compensatory techniques to accommodate their loss of function ${ }^{25}$. Jørgensen et al..$^{26}$ in their community based study found that most functional recovery in ADL including personal management was achieved within 12.5 weeks by $95 \%$ of their participants with stroke and that $80 \%$ of participants reached maximum functional recovery level within six weeks post stroke.

Literature suggests that inpatient management should thus focus more on functional independence in personal management skills, including eating, hygiene tasks, dressing and grooming as these are crucial for social interaction and social participation. A sense of self efficacy is experienced by stroke survivors who achieve independence in personal management ${ }^{27}$ and a lack of participation in personal management activities can lead to a breakdown in habits as well as physiological deterioration ${ }^{28}$. Independence in personal management has been deemed important for the maintenance of homeostasis, neuronal physiology and mental capacity at peak levels, all of which are associated with a sense of self-worth and which stimulate societal relationships ${ }^{29}$.

Therefore, within the context of the public hospital where the study was conducted, the objectives of this study were: -

$*$ to establish the profile of the dysfunction with which stroke survivors present as well as the recovery their upper limb movement and independence in personal management on referral, at discharge and for two months post discharge.

* to establish the correlation between their upper limb movement and independence in personal management on referral, at discharge and for two months post discharge.

\section{RESEARCH METHODS}

A quantitative, descriptive, correlational, longitudinal research design was used to describe the recovery of upper limb mobility and personal management of stroke survivors attending occupational therapy over time while hospitalised and within the first two months post discharge.

\section{Sampling}

Total population sampling of patients with first time stroke referred for rehabilitation at the hospital over a two-month period was used for this study. Patients that met the inclusion criteria were invited to participate ${ }^{30,31}$. Patients in the age range 18 and 75 years and who were medically stable on referral were considered eligible for the study. Only patients who were medically stable were included in order to safely assess the motor functioning and performance 
in personal management. Patients with low level of consciousness and uncontrolled hypertension on referral were excluded from the study.

Based on Cochran's sample size formula it was estimated that for the 100 stroke survivors that met the inclusion criteria, a sample of 59 was required for this study. This sample size allowed a margin of error that the sample was representative of the population set at $0.05^{32}$.

\section{Research Instruments}

The Fugl-Meyer Assessment Upper Extremity (FMA UE) ${ }^{33}$ outcome measure was used for the assessment of the upper limb motor dysfunction and provide evidence for recovery of the patients with stroke. The assessment consists of a 68-point motor domain scale that evaluates changes in motor impairment within the upper limb after stroke. It has a 3-point scoring system: a score of $(0)$ indicates no movement noted, (I) reports that the movement is poor and (2) means a full range of movement has been achieved ${ }^{34}$. In the upper limb section movement in the arm, wrist and hand are assessed as well as co-ordination of the movement. The FMA UE has been proven to be reliable with adequate inter-rater reliability $(r=0.99)$, test retest reliability (ICC $=$ $0.97)$ and internal consistence $(\alpha=0.97)^{35}$. Convergent validity with Functional Index Measure was found at a $95 \%$ confidence interval at $\rho<0.0 \mathrm{I}^{36}$

The South African Data Functional Medicine (SADFM) Beta Scale ${ }^{\circledR 37}$ is an outcome measure standardised in South Africa to assess independence in the personal management of patients with disability for use by nurses and therapists working in rehabilitation, convalescent, gerontology and long term care facilities. The scale assesses four subscales including self-care, toileting, mobilisation and cognition. There are 13 items related to personal management. Cognition was not included in this study.

The activities assessed included simulated eating with a spoon; brushing hair and teeth; washing in a basin using a face cloth and soap; dressing upper and lower body with a loose shirt and loose pants. Transfers to different surfaces in the gym from wheelchair to chair, toilet and bath tub were observed. Locomotion was assessed by pushing a wheelchair or walking over a smooth 50-meter surface. Participants were also required to walk up and down a flight of 10 stairs.

Performance was observed and measured by using an ordinal scale ranging from I-7. Scores indicate the level of dependence for personal management as follows:

I-2 total assistance

2 supervision is required for $<50 \%$ of the task, does $<50 \%$ of the task with constant supervision

4 moderate assistance - needs set up, intermittent supervision and does $>50 \%$ of the task without supervision

5-6 modified independence with no supervision but set up, cueing, assistive devices or extra time

7 independent participation

The SADFM Beta Scale provides evidence on the effectiveness of intervention and is therefore suitable for use in research studies. Since it was developed for patients in subacute settings, a pilot study on five patients was completed to ensure the responsiveness of the measure in acute settings. Adequate responsiveness on all items was found. The construct validity has been confirmed using the Rasch analysis with internal construct validity for item reliability and person reliability ranging from 0.93 to $0.76^{38}$.

\section{Research procedure}

Once ethical clearance had been received from the Human Research Ethics Committee at the University of the Witwatersrand (MI3I036) and permission had been received from the hospital, 59 first stroke survivors aged between 18 and 75 years of age, that were medically stable were identified by the occupational therapists and recruited into the study if they or their families gave informed consent.

The researcher collected the first set of data for all the participants before any occupational therapy was initiated. Demographic information, occupational background and living context as well as current and previous medical history was obtained from the patient or family if the participant had aphasia. The FMA UE measure and SADFM Beta Scale were used to record upper limb motor function and personal management performance. During the course of this research study the participants continued to receive routine therapy and hospital care. The main focus of occupational therapy intervention in the occupational therapy department where this research was completed was to improve motor performance based on the Carr and Shepherd motor re-learning framework ${ }^{39}$ which centred on optimal task performance in reaching with the hand and manipulation, addressed together with upper limb mobility. The intervention encouraged patients to actively participate and focus on practicing observed tasks in varying conditions, whilst incorporating newly acquired mobility. Components from theorists such as Rood, Brunnstrom and Bobath were also incorporated into treatment sessions ${ }^{24}$.

The second data collection session using the FMA UE measure and SADFM Beta Scale was completed prior to the participants' discharge. Some participants were not assessed at this time as they were deceased and others were discharged over the weekend when there had been no indication that discharge was imminent. All participants who returned at month I and month 2 post discharge were assessed again at each follow up appointment and the FMA UE and SADFM Beta Scale was used to record further change in upper limb motor function and personal management.

\section{Data Analysis}

Descriptive statistics was used to describe the demographics of the sample using means, frequencies and standard deviations $\mathrm{s}^{40}$. The outcomes of the FMA UE and SADFM Beta Scale of participants were analysed using the medians and frequencies due to the ordinal nature of the data. TIBCO Statistica ${ }^{\circledR} \mathrm{vI} 3.3^{41}$ was used to compare the outcome measurements at the four assessment intervals (referral, discharge, I and 2 months' post discharge) using non-parametric Chi squared tests. Missing data and deceased participants' data were not included in the analysis.

A non-parametric Spearman's rank order correlation was used to determine if any association existed between the scores for the FMA UE and the SADFM Beta Scale on referral and discharge from hospital as well as when participants were receiving out-patient rehabilitation for two months.

\section{RESULTS}

\section{Sample}

Of the 59 participants recruited on admission, $22 \%(n=13)$ of the participants died while in hospital reducing the total sample to 46 participants. One participant remained in hospital over the entire study period and was excluded from the study with the results of the other 45 participants assessed on referral. From this cohort $26.6 \%(n=12)$ were discharged unexpectedly over the weekends making it impossible for a discharge assessment to be completed. The 33 participants reassessed on discharge therefore resulted in a loss to follow up of $26.6 \%$. Two assessments were done during outpatient follow up at month I and 2 post discharge. At month I, $60.6 \%(n=20)$ participants assessed on discharge returned for follow up, which was reduced to $45.4 \%(n=15)$ at month 2 post discharge. Thus, there was a further loss to follow up of $54.5 \%$ $(n=18)$ after discharge, with a total loss to follow up at month 2 from referral of $66.6 \%(n=30)$.

The demographics of the 45 participants assessed at referal indicated the participants had a mean age of 45.84 years with an age range between 23 years and 72 years. About $44.4 \%$ were in the age bracket of $31-50$ years. Males made up $44.4 \%$ of participants, with $55.6 \%$ being female. Although there was a 


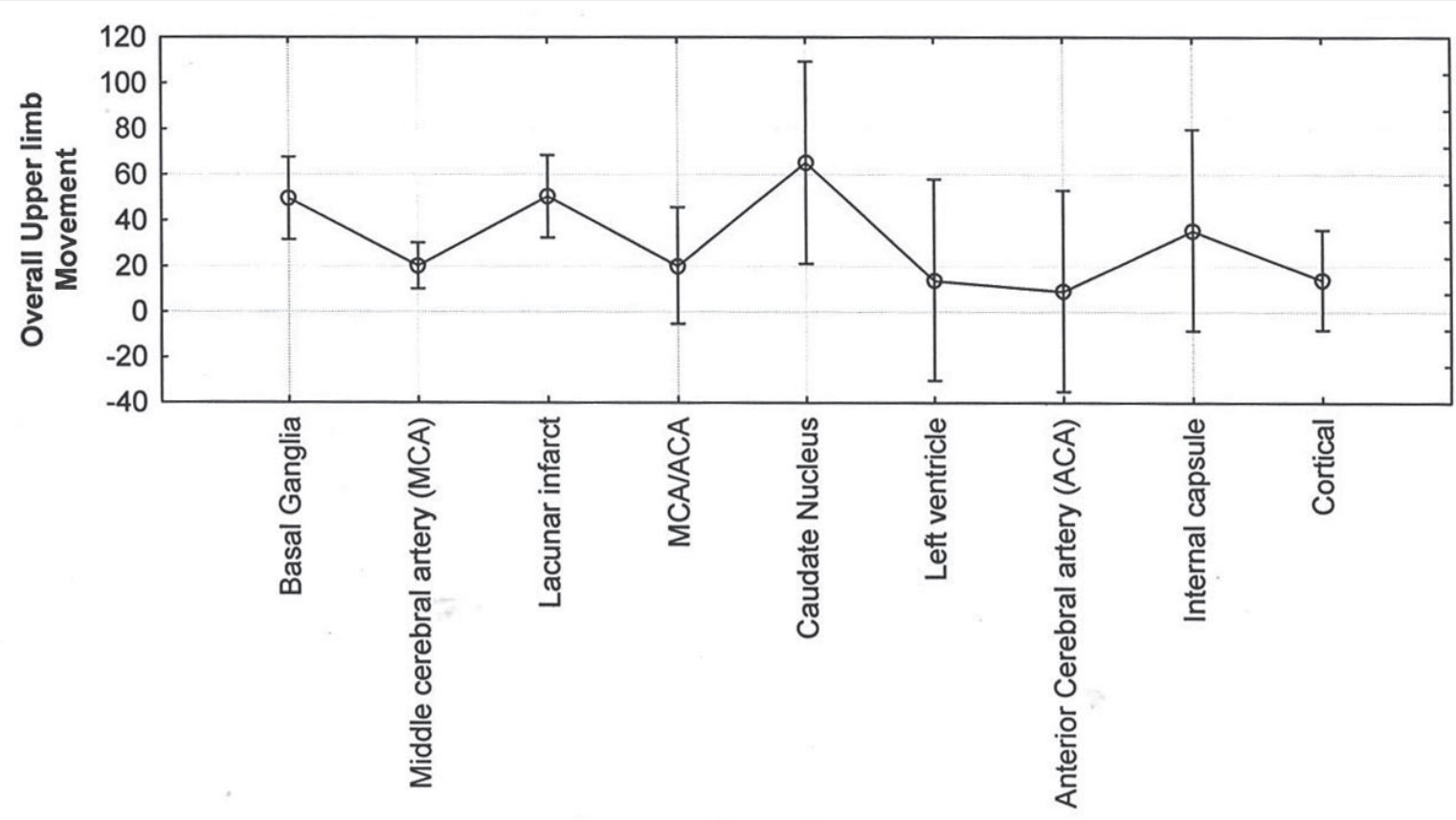

Type of stroke

Figure I: Overall upper limb movement scores of the Fugl-Meyer Assessment Upper Extremity on referral for site of stroke $(n=45)$

decline in the number of participants over the four assessment periods, there was no significant change in any of the demographic variables for the participants who dropped out and continued with therapy.

\section{Medical History}

Participants were hospitalised for a mean of eight days (range 3-30 days). More than $75 \%$ of participants presented with ischemic strokes with either left $(48.3 \%)$ or right $(51.7 \%)$ sided strokes. The most common site of stroke was in the middle cerebral artery (MCA) $(38.7 \%)$, followed by stroke in anterior cerebral artery (ACA) $(2.04 \%)$ and combined MCA and ACA (6. I $2 \%)$. The latter were associated with greatest loss of upper limb function. These included $2.04 \%$ of participants with a left ventricle lesion and $8.8 \%$ with cortical strokes, which had non-significant lower scores $(\mathrm{p}=0.432)$ on the FMA UE on referral (Figure I above).

The co-morbidities most frequently reported were hypertension $(29.6 \%)$ and HIV+ status $(23.9 \%)$. There was no significant difference for overall upper limb movement on referral according to comorbidities. Upper limb function was also not found to differ significantly according to demographic factors such as age or gender.

\section{Upper Limb Function}

Table I below indicates that upper limb function improved significantly for all aspects from referral to discharge when patients were receiving intense inpatient therapy in the first week after admission. The participants who returned at month I had a significantly lower median score for all upper limb components as they were those that had been discharged with deficits in upper limb movement. Little to no improvement occurred in their upper limb function in the month after discharge. A slight non-significant increase of upper limb function but not hand or wrist movement was seen at month 2 .

On referral $13 \%(6)$ of participants presented with full upper limb movement, $2.2 \%$ (I) with full wrist movement and $4.4 \%$ (2) presented with full in hand movements. All participants scored 0 for coordination at this stage. On discharge $36.3 \%$ (I2) of the participants assessed achieved full upper limb function, as well as full wrist and hand movement and $34 \%$ (II) had a full score for co-ordination after in-patient occupational therapy.

Table I: Median scores on the Fugl-Meyer Assessment Upper Extremity at the four assessment points in the study

\begin{tabular}{|c|c|c|c|c|c|c|c|c|}
\hline \multirow{2}{*}{\multicolumn{2}{|c|}{$\begin{array}{l}\text { Fugl-Meyer Assessment: } \\
\text { Upper Extremity measure }\end{array}$}} & $\begin{array}{c}\text { Referral } \\
(n=45)\end{array}$ & $\begin{array}{l}\text { Discharge } \\
(n=33)\end{array}$ & \multirow{2}{*}{$\begin{array}{l}\text { p value } \\
\text { Change } \\
\text { from } \\
\text { referral to } \\
\text { discharge }\end{array}$} & $\begin{array}{l}\text { Month I } \\
(n=20)\end{array}$ & \multirow{2}{*}{$\begin{array}{l}\text { p value } \\
\text { Change } \\
\text { from } \\
\text { discharge } \\
\text { to Month I }\end{array}$} & $\begin{array}{c}\text { Month } 2 \\
(n=15)\end{array}$ & \multirow{2}{*}{$\begin{array}{l}\text { P value } \\
\text { Change } \\
\text { month I to } \\
\text { month } 2\end{array}$} \\
\hline & & \multicolumn{2}{|c|}{$\begin{array}{c}\text { Median } \\
\text { (Lower and upper quartile) }\end{array}$} & & $\begin{array}{l}\text { Median (Lower } \\
\text { and upper } \\
\text { quartile) }\end{array}$ & & $\begin{array}{c}\text { Median (Lower } \\
\text { and upper } \\
\text { quartile) }\end{array}$ & \\
\hline \multirow[t]{4}{*}{$\begin{array}{l}\text { Upper limb } \\
\text { movement }\end{array}$} & Arm & $\begin{array}{c}66.67 \\
(16.67-83.33)\end{array}$ & $\begin{array}{c}79.17 \\
(18.05-100.00)\end{array}$ & $0.001 * *$ & $\begin{array}{c}54.83 \\
(31.95-100.00)\end{array}$ & $0.009 * *$ & $\begin{array}{c}63.89 \\
(16.67-100.00)\end{array}$ & 0.715 \\
\hline & Wrist & $\begin{array}{c}0.00 \\
(0.00-50.00)\end{array}$ & $\begin{array}{c}30.00 \\
(0.00-100.00)\end{array}$ & $0.001 * *$ & $\begin{array}{c}45.00 \\
(0.00-100.00)\end{array}$ & 0.208 & $\begin{array}{c}0.00 \\
(0.00-100.00)\end{array}$ & 0.179 \\
\hline & Hand & $\begin{array}{c}33.3 \\
(0.00-57.14)\end{array}$ & $\begin{array}{c}64.28 \\
(0.00-100.00)\end{array}$ & $0.003 * *$ & $\begin{array}{c}42.86 \\
(0.00-100.00)\end{array}$ & 0.236 & $\begin{array}{c}31.94 \\
(0.00-100.00)\end{array}$ & 0.067 \\
\hline & Coordination & $\begin{array}{c}0.00 \\
(0.00-30.00)\end{array}$ & $\begin{array}{c}0.00 \\
(0.00-100.00)\end{array}$ & $0.003 * *$ & $\begin{array}{c}0.00 \\
(0.00-100.00)\end{array}$ & $0.024 *$ & $\begin{array}{c}0.00 \\
(0.00-100.00)\end{array}$ & 0.108 \\
\hline
\end{tabular}




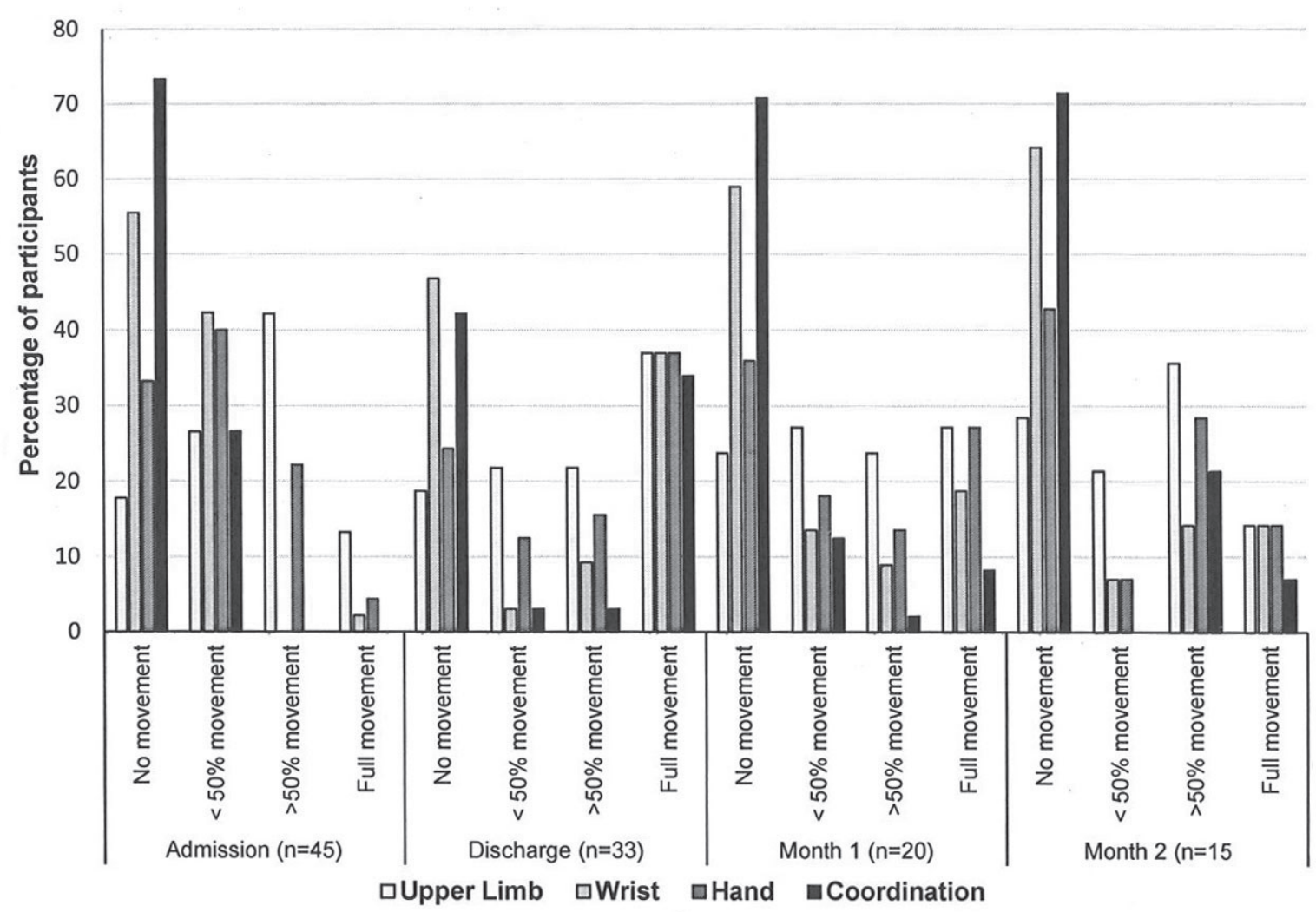

Figure 2: Fugl-Meyer Assessment Upper Extremity at the four assessment points in the study

Of the participants assessed at discharge $63.7 \%$ (2I) still had varying recovery of motor function with the greatest deficits being for wrist movement and coordination (Figure 2).

Of the participants who returned at month I, $27.2 \%(5)$ had regained full movement of the upper limb and hand but not the wrist and with only one participant having a full score for coordination. Fifty percent $(10)$ participants still presented with no movement or less than $50 \%$ movement for the upper on the FMA-UE at month I and at month 2. These participants that attended at month 2 follow up presented with little or no improvement in upper limb function from month I.

\section{Personal Management}

During the period of inpatient care, the scores for self-care toileting and mobility improved significantly by discharge after the participants had attended therapy, which focused on increasing independence in this domain. Although $100 \%$ of participants achieved independence or modified independence in eating and bowel and bladder control by discharge, lower quartiles in the results for other activities indicated that a number of participants still required assistance particularly with bathing, dressing, toileting, transfers and locomotion.

The participants' ADL scores had improved significantly at the month I assessment, except for eating which was consolidated during inpatient care. Participants continued to have dependence in the same areas identified as problems on discharge, but made gains in independence while at home for a month. There was no further significant improvement seen at the month 2 assessment, except for locomotion: stairs (Table II on page II).

\section{Self-Care}

The change in the personal management scores on the SADFM Beta Scale varied between the different activities. While most participants were independent in eating, the scores for dressing and bathing showed marked dependence on referral. The majority of participants (57\%: 26) scored I-2 or 3-4 indicating dependence or the need for moderate assistance on referral (Figure 3 on page II).
Nearly half of the participants (49\%: 16 ) had achieved independence in this domain while a further $24 \%$ (8) had achieved modified independence by discharge. Only 28\%(9) participants still remained dependent, particularly with bathing and lower limb dressing after receiving inpatient therapy.

The improvement in the level of independence in self-care from month I to month 2 of outpatient care showed no significant improvement. At month I fewer participants required assistance, as more participants that returned for outpatient therapy, were using modified independence due to their upper limb motor deficits. At this stage only $9 \%(4)$ participants needed assistance in self-care. At month 2, although the participants who did return for follow up at this stage had become more independent with the exception of one participant. (Figure 3).

\section{Toileting}

The scores for toileting indicated the greatest percentage of participants (5l\%: $n=23$ ) were independent or had modified independence in this domain on referral. The scores for bowel and bladder management showed independence was achieved for this aspect in hospital and maintained once the participants were at home. Independence in toileting remained a greater challenge than bowel and bladder management even though the majority of participants did achieve independent in this domain of personal management. Some participants were dependent throughout the study for toileting with $12 \%$ (2) of participants still requiring assistance at month 2 (Figure 4 on page 12).

\section{Mobility}

Mobility was the domain most affected with $47 \%$ (2I) participants being totally dependent on referral. Although scores in this domain did improve significantly during the inpatient treatment phase, $24 \%$ (9) of participants remained dependent or required assistance with mobility including transfers and locomotion on discharge (Figure 5 on page 12).

At month I, $25 \%$ (5) participants were still dependent or needed assistance with mobility. These same five participants 
Table II: Scores on the South African Data Functional Medicine Beta Scale at the four assessment points in the study

\begin{tabular}{|c|c|c|c|c|c|c|c|c|}
\hline \multirow{2}{*}{\multicolumn{2}{|c|}{$\begin{array}{l}\text { South African Data: } \\
\text { Functional Medicine -Beta } \\
\text { Scale }\end{array}$}} & $\begin{array}{c}\text { Referral } \\
(n=45)\end{array}$ & $\begin{array}{l}\text { Discharge } \\
(n=33)\end{array}$ & \multirow{3}{*}{$\begin{array}{c}\text { p value } \\
\text { Change from } \\
\text { referral to } \\
\text { discharge }\end{array}$} & $\begin{array}{l}\text { Month I } \\
(n=20)\end{array}$ & \multirow{3}{*}{$\begin{array}{l}\text { P value } \\
\text { Change from } \\
\text { discharge to } \\
\text { Month I } \\
0.108\end{array}$} & \multirow{3}{*}{$\begin{array}{c}\begin{array}{c}\text { Month } 2 \\
(n=15)\end{array} \\
\begin{array}{c}\text { Median } \\
\text { (Lower and } \\
\text { upper quartile) }\end{array} \\
\begin{array}{c}7 \\
(7-7)\end{array}\end{array}$} & \multirow{3}{*}{$\begin{array}{c}\mathrm{P} \text { value } \\
\text { Change } \\
\text { month I to } \\
\text { month } 2 \\
0.654\end{array}$} \\
\hline & & \multicolumn{2}{|c|}{$\begin{array}{c}\text { Median } \\
\text { (Lower and upper quartile) }\end{array}$} & & $\begin{array}{l}\text { Median (Lower } \\
\text { and upper } \\
\text { quartile) }\end{array}$ & & & \\
\hline \multirow[t]{5}{*}{ Self-care } & Eating & $\begin{array}{c}7 \\
(7-7)\end{array}$ & $\begin{array}{c}7 \\
(7-7)\end{array}$ & & $\begin{array}{c}7 \\
(7-7)\end{array}$ & & & \\
\hline & Grooming & $\begin{array}{c}5 \\
(4-7)\end{array}$ & $\begin{array}{c}7 \\
(5-7)\end{array}$ & $0.001 * *$ & $\begin{array}{c}7 \\
(7-7)\end{array}$ & $0.007 * *$ & $\begin{array}{c}7 \\
(7-7)\end{array}$ & 0.248 \\
\hline & Bathing & $\begin{array}{c}4 \\
(3-7) \\
\end{array}$ & $\begin{array}{c}5 \\
(4-7) \\
\end{array}$ & $0.001 * *$ & $\begin{array}{c}7 \\
(5-7) \\
\end{array}$ & $0.005 * *$ & $\begin{array}{c}7 \\
(5-7) \\
\end{array}$ & 0.50 \\
\hline & $\begin{array}{l}\text { Dressing Upper } \\
\text { body }\end{array}$ & $\begin{array}{c}4 \\
(3-7)\end{array}$ & $\begin{array}{c}7 \\
(4-7) \\
\end{array}$ & $0.001 * *$ & $\begin{array}{c}7 \\
(5-7) \\
\end{array}$ & $0.003 * *$ & $\begin{array}{c}7 \\
(5-7) \\
\end{array}$ & 0.715 \\
\hline & $\begin{array}{l}\text { Dressing Lower } \\
\text { body }\end{array}$ & $\begin{array}{c}4 \\
(3-7)\end{array}$ & $\begin{array}{c}6 \\
(3-7)\end{array}$ & $0.001 * * *$ & $\begin{array}{c}7 \\
(4-7)\end{array}$ & $0.017 *$ & $\begin{array}{c}7 \\
(4-7)\end{array}$ & 0.294 \\
\hline \multirow[t]{3}{*}{ Toileting } & Toileting & $\begin{array}{c}5 \\
(2-7)\end{array}$ & $\begin{array}{c}6 \\
(3-7)\end{array}$ & $0.001 * *$ & $\begin{array}{c}7 \\
(4-7)\end{array}$ & $0.001 * *$ & $\begin{array}{c}7 \\
(5-7)\end{array}$ & 0.201 \\
\hline & $\begin{array}{c}\text { Bladder } \\
\text { management }\end{array}$ & $\begin{array}{c}7 \\
(6-7) \\
\end{array}$ & $\begin{array}{c}7 \\
(6-7) \\
\end{array}$ & $0.008^{* *}$. & $\begin{array}{c}7 \\
(6-7) \\
\end{array}$ & $0.017 *$ & $\begin{array}{c}7 \\
(6-7) \\
\end{array}$ & 1.00 \\
\hline & $\begin{array}{c}\text { Bowel } \\
\text { management }\end{array}$ & $\begin{array}{c}7 \\
(6-7)\end{array}$ & $\begin{array}{c}7 \\
(6-7)\end{array}$ & $0.007^{* *}$. & $\begin{array}{c}7 \\
(6-7)\end{array}$ & $0.027^{*}$ & $\begin{array}{c}7 \\
(6-7)\end{array}$ & 1.00 \\
\hline \multirow[t]{5}{*}{ Mobility } & $\begin{array}{l}\text { Transfers: Bed } \\
\text { to chair }\end{array}$ & $\begin{array}{c}6 \\
(3-7) \\
\end{array}$ & $\begin{array}{c}7 \\
(4-7) \\
\end{array}$ & $0.001 * *$ & $\begin{array}{c}7 \\
(5-7) \\
\end{array}$ & $0.007 * *$ & $\begin{array}{c}7 \\
(7-7) \\
\end{array}$ & 1.00 \\
\hline & $\begin{array}{l}\text { Transfers: Chair } \\
\text { to toilet }\end{array}$ & $\begin{array}{c}6 \\
(3-7)\end{array}$ & $\begin{array}{c}7 \\
(4-7)\end{array}$ & $0.001 * *$ & $\begin{array}{c}7 \\
(5-7)\end{array}$ & $0.013^{*}$ & $\begin{array}{c}7 \\
(7-7)\end{array}$ & 1.00 \\
\hline & Transfers: Chair & $\begin{array}{c}5.5 \\
(2-7) \\
\end{array}$ & $\begin{array}{c}7 \\
(3-7) \\
\end{array}$ & $0.001 * *$ & $\begin{array}{c}7 \\
(5-7) \\
\end{array}$ & $0.007 * *$ & $\begin{array}{c}7 \\
(6-7) \\
\end{array}$ & 0.855 \\
\hline & $\begin{array}{l}\text { Locomotion: } \\
\text { Walk/ }\end{array}$ & $\begin{array}{c}6 \\
(1-7) \\
\end{array}$ & $\begin{array}{c}6 \\
(3-7) \\
\end{array}$ & $0.001 * *$ & $\begin{array}{c}6 \\
(4-7) \\
\end{array}$ & $0.011 *$ & $\begin{array}{c}6 \\
(6-7) \\
\end{array}$ & 0.465 \\
\hline & $\begin{array}{l}\text { Locomotion: } \\
\text { Stairs }\end{array}$ & $\begin{array}{c}6 \\
(1-7)\end{array}$ & $\begin{array}{c}6 \\
(1-6)\end{array}$ & $0.001 * *$ & $\begin{array}{c}6 \\
(1-7)\end{array}$ & $0.17 *$ & $\begin{array}{c}6 \\
(I-7)\end{array}$ & $0.043^{*}$ \\
\hline
\end{tabular}

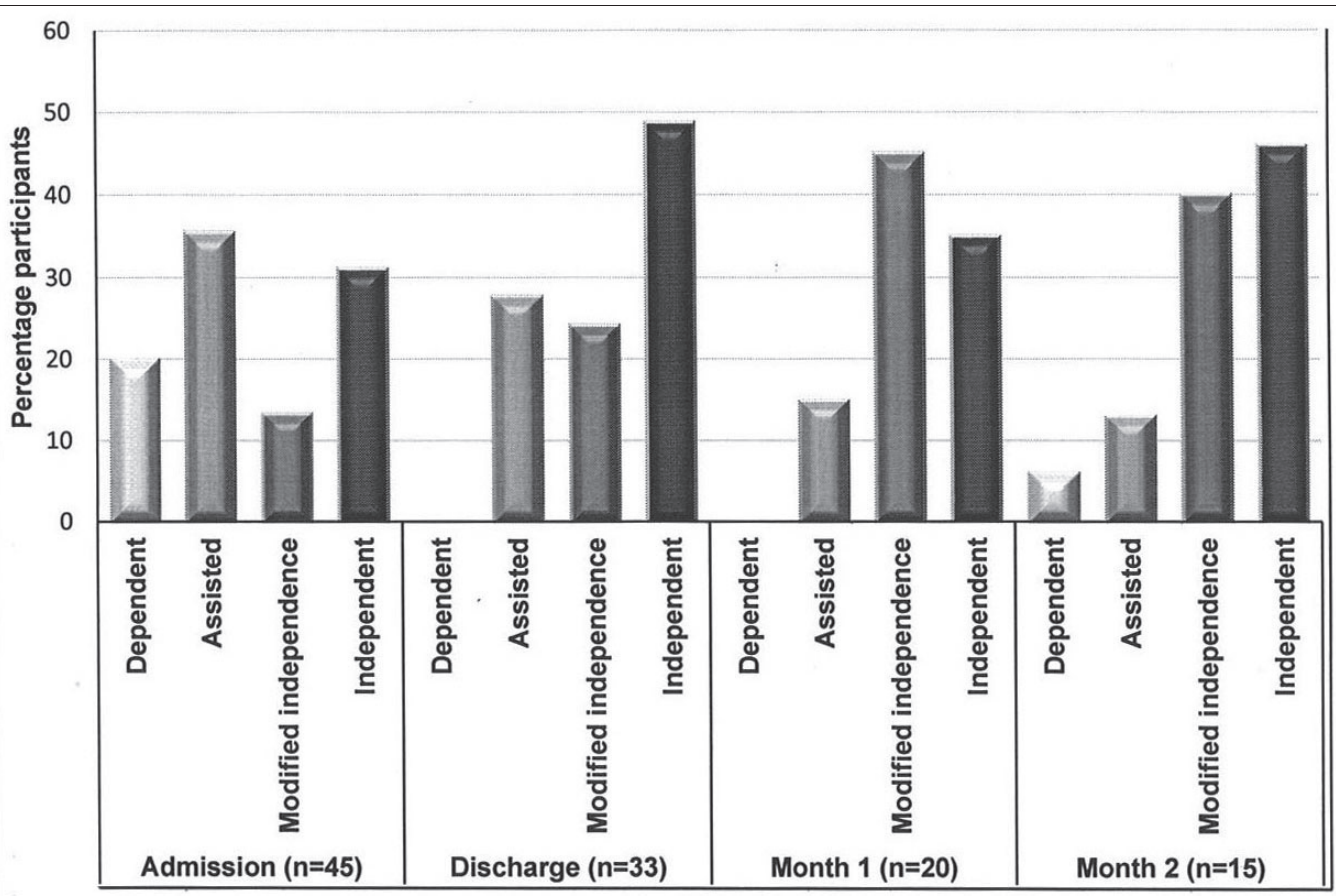

Figure 3: Level of function for self-care on the South African Data Functional Medicine Beta Scale at four assessment points in the study 


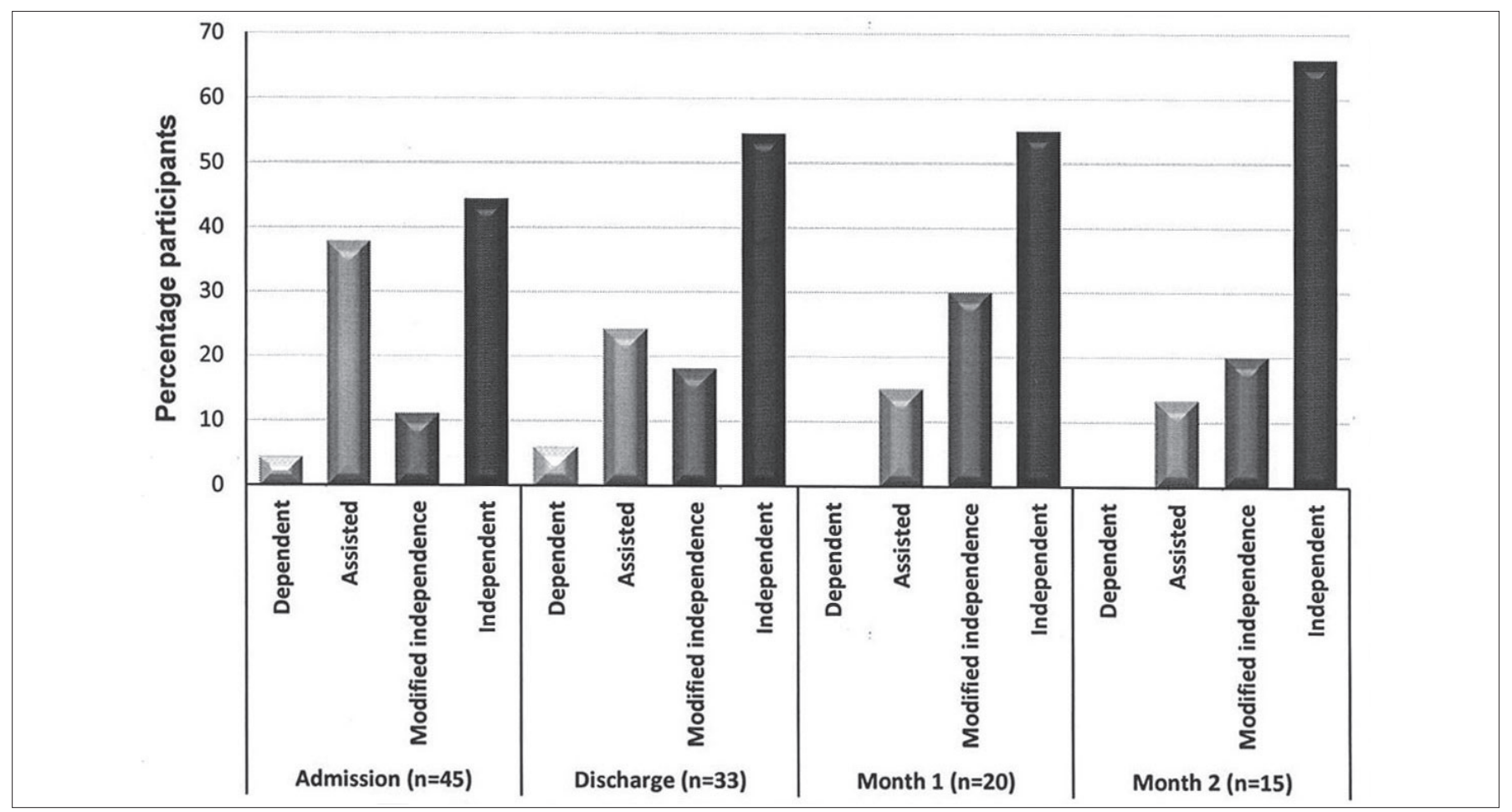

Figure 4: Level of function for toileting on the South African Data Functional Medicine Beta Scale at four assessment points in the study

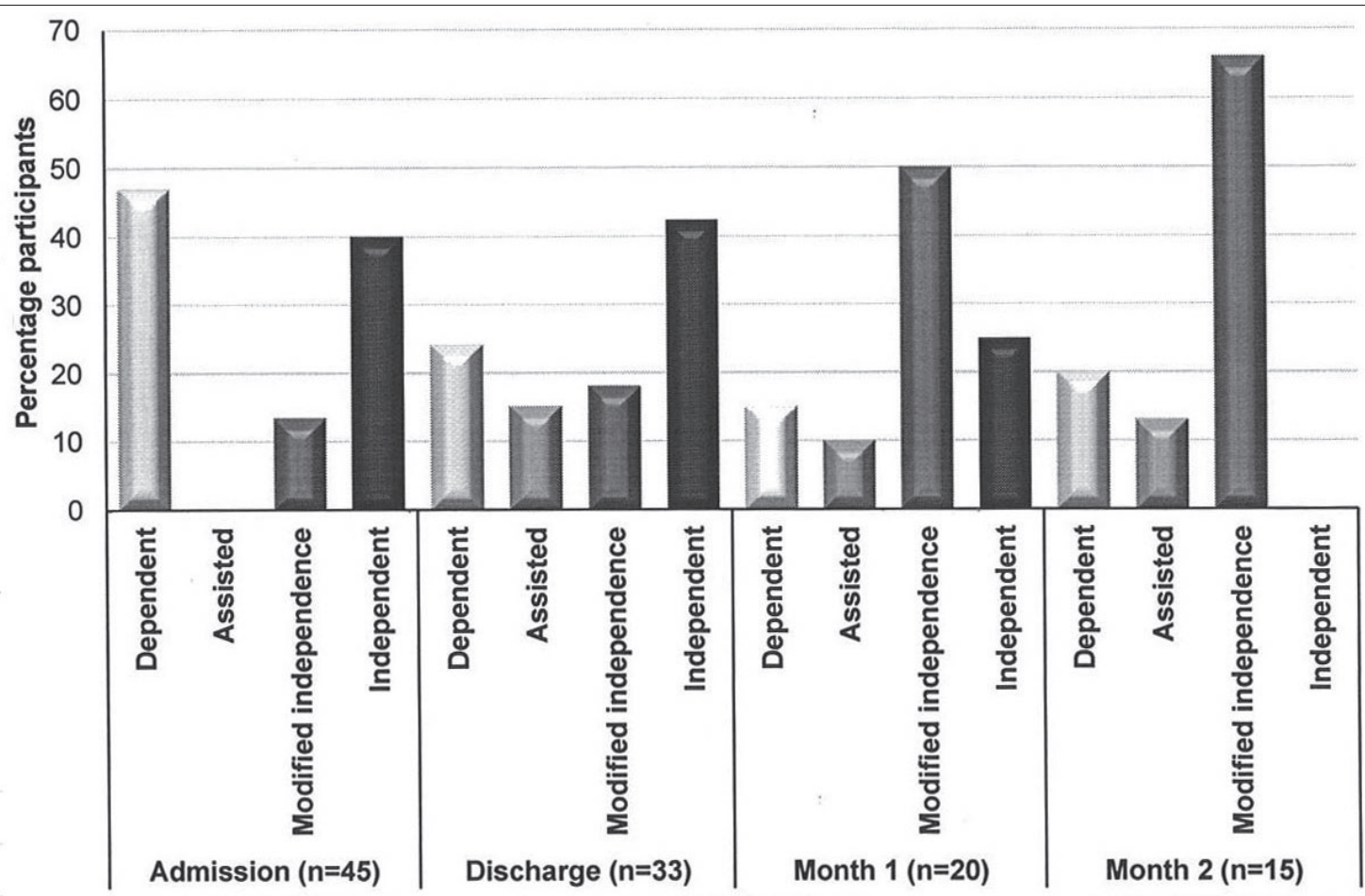

Figure 5: Level of function for mobility on the South African Data Functional Medicine Beta Scale at four assessment points in the study

remained dependent at month 2. Participants who were independent in mobility did not return for the month 2 assessment but locomotion remained a challenge for $66 \%(10)$ participants who used modified independence.

\section{Correlation between Personal Management and Upper Limb Function}

The scores for self-care, toileting and mobility on the SADFM Beta Scale were correlated with the overall motor recovery of the upper limb, wrist, hand and coordination of the FMA UE to determine the association between the variables at the four assessment points (Table III on page 20).

When the assessment scores for the SADFM Beta Scale and FMA UE were correlated, there were strong correlations evident at discharge. At this stage the participant's ability to engage in personal management activities was associated with their function in the upper limb.

At month I and 2 no correlation between upper limb motor function and personal management was found, confirming the findings above that most participants had achieved adequate inde- 
Table III: Correlation between scores for the South African Data Functional Medicine Beta Scale and the Fugl-Meyer Assessment Upper Extremity measure at four assessment points

\begin{tabular}{|l|c|c|c|c|}
\hline \multirow{2}{*}{$\begin{array}{l}\text { South African Data Functional } \\
\text { Medicine-Beta Scale }\end{array}$} & Fugl-Meyer Assessment: Upper Extremity & Month I & Month 2 \\
\cline { 2 - 5 } & Referral & Discharge & $r$ & $r$ \\
\cline { 2 - 5 } & $r$ & $r$ & 0.14 & -0.02 \\
\hline Self-care & 0.26 & $0.66 *$ & 0.14 & -0.06 \\
\hline Toiling & -0.04 & $0.75 *$ & 0.11 & -0.11 \\
\hline Mobility & -0.16 & $0.59 *$ & & \\
\hline Significance & $*$ \\
\hline
\end{tabular}

pendence at this stage even though their upper limb motor function remained problematic.

\section{DISCUSSION}

The high percentage of participants with stoke between the ages of 31 to 50 years in this study confirms the prevalence of strokes in a relatively younger age group in the South African context ${ }^{42,43}$. This may be associated with the high incidence of the co-morbidity of HIV+ status and endemic hypertension with a prevalence of approximately $45 \%$ for $35-55$ year olds in South Africa ${ }^{44}$.

Slightly more females presented with stoke in the current study. The much higher incidence of stroke in females related to higher rates of hypertension and HIV in females ${ }^{45}$, was not found for the current study where these comorbidities occurred in less than $30 \%$ of female participants ${ }^{43,46}$.

The total $66.6 \%$ loss to follow up was lower than the $84 \%$ reported for stroke patients returning to public hospitals by Ntamo et al. ${ }^{16}$. The mean length of an eight day hospital stay was in line with that reported in other studies ${ }^{2,3}$.

The higher incidence of ischaemic stroke found in the current study is also supported by the literature $e^{47.48}$ with no difference in recovery on this variable as supported by Hendricks et $\mathrm{al}^{21}$. The only factor influencing upper limb motor function was identified as the site of lesion of the stroke. Participants with cerebral artery, left ventricle and cortical strokes presented with less motor function of the upper limbs on referral and these were the participants that returned for therapy as outpatients due to loss of function in their upper limbs. This finding was supported by de Nap and Reding ${ }^{22}$ who found that only approximately $10 \%$ of the patients with cortical and subcortical stroke affecting the premotor area and supplementary motor area supplied by the cerebral arteries, recovered upper limb movements 2-3 months post stroke. All of the participants with strokes in sub-cortical regions such as the lacunar area achieved full recovery of upper limb motor function, which concurred with findings from previous studies ${ }^{10,49}$.

\section{Upper limb motor recovery and personal management post stoke}

This study confirmed that the FMA UE was sensitive to changes of upper limb motor function of stroke participants at four assessment intervals. Overall there was a significant improvement in all aspects of upper limb function by discharge and for the upper limb and hand at month I post discharge, the improvement varied from participant to participant. The results were impacted by the 12 participants who were discharged without being reassessed as 10 of these participants had had full recovery or $>50 \%$ recovery of upper limb mobility on referral. Only two participants with $<50 \%$ recovery were discharged without the therapists being informed. It appears, therefore, that patients being discharged without consultation with the rehabilitation team are mostly those that have full recovery of movement soon after admission to hospital. This discharge practice remains an issue for follow up of patients and the functioning of a comprehensive multidisciplinary team to address stroke in public hospitals.
The recovery of upper limb function in $37 \%$ of participants at discharge and $20 \%$ of participants in month I in this study, was higher than the $35 \%$ reported by Kwakkel et al. ${ }^{10}$ for patients in the first 4-6 weeks post stroke. This can be accounted for by the younger age of the participants as well as the site of the strokes being more varied, with a higher percentage of basal ganglia, lunar and caudate nucleus infarcts associated with HIV infection ${ }^{50}$. The $17.7 \%$ of participants with these lesions already had some motor recovery on referral, which is a good predictor for full recovery of upper limb motor function ${ }^{51}$.

On analysis it was established that loss to follow up was Missing Not at Random (MNAR) ${ }^{52}$ as all participants who were lost to follow at month I had $>80 \%$ recovery of the upper limb and scores for full independence or modified independence in personal management. Therefore, participants who returned at month I were those with limited or no return of motor function at 5-8 weeks post stroke. Fifty percent of these participants presented with lack of movement or synergistic movements and poor isolated and coordinated movements of the fingers, which prevented production of energy efficient and effective functional use of the affected upper $\mathrm{lim}^{22}$. The improvement at month 2 was also small and only two participants continued to show an improvement in upper limb movement at this stage while receiving monthly outpatient treatment and a home programme. This lack of significant improvement in motor function may be attributed to the lack of intensive therapy post discharge, as according to Jette et al. ${ }^{53}$ the odds of improving upper limb mobility is associated with increasing intensity of therapy.

Although independence and modified independence in selfcare improved significantly for all aspects during the participants' hospitalisation, toileting was achieved by more than $70 \%$ of the participants, while nearly $60 \%$ were independent or had modified independence in mobility. The findings of this research still indicated higher levels of independence in personal management than in a previous study in the Western Cape using the Barthel Index, which found only $21 \%$ of stroke survivors were independent with minimal assistance on discharge ${ }^{3}$. However, the mean age of the participants in the Western Cape study was more than 10 years older than the sample in the current study, which may account for the outcomes found. Age was one of the main predictors of personal management outcomes confirmed in the Western Cape study ${ }^{3}$ but was not a predictor in the current study.

The significant increase in personal management post discharge has been reported in other South African studies ${ }^{3,15}$. This supports the consolidation in the use of compensatory methods taught while in hospital. Although, these techniques do contribute to independence before discharge due to the short hospital stay participants did not achieve the 20 hours of practice needed to become proficient at adapted techniques ${ }^{14}$. The percentage of participants who were independent in bathing, dressing and toileting was similar for all the studies post discharge but in the current study, a much higher percentage of participants were independent for mobility and transfers ${ }^{3}$. Again, this may be age-related, although in the current study mobility was also the domain on the SADFM Beta Scale where the greatest residual dependence was recorded at the end of month ${ }^{2}$. 
Deterioration in self-care was seen at month 2 post stroke in one participant, where the family completed these activities for the participant. This may be related to the problem of providing adequate stroke education on or before discharge due to a short hospital stay and weekend discharges. This is supported by a study on stroke survivors in KwaZulu Natal where two thirds of families did not receive any education on stroke and care of their family member ${ }^{15}$.

Although there was only a low correlation between upper limb function and personal management on referral, after a few days of intense therapy the participants' FMA UE scores correlated strongly with their SADFM Beta Scale scores as the therapy targeted both upper limb function and independence in personal management, including the use of compensatory methods. Therefore correlation between upper limb motor function and independence in personal management were moderate to strong on discharge with the exception of eating and some transfers and locomotion. This indicates the importance of upper limb movement for all components of personal management including transfers especially those which require bilateral hand use. Independence in bathing, dressing, toileting as well as bowel and bladder management all had a strong association to arm and hand recovery on discharge of the participants. Bowel and bladder management at this stage correlated strongly with upper limb function, wrist and hand movement. This was probably due to participants still receiving assistance in the form of nappies from nursing staff in the hospital, if they did not have the upper limb motor function and mobility to toilet independently, even if they were continent.

This relationship changes post discharge once the participants, even those with upper limb motor deficits, have had an opportunity to practice and use compensatory techniques for their personal management at home. This correlation was not maintained at month I and month 2 since although the participants who returned at this stage had limited upper limb function, their personal management continued to improve significantly. This is because the participants were using compensatory methods learnt during rehabilitation to achieve independence in personal management, irrespective of the return of upper limb motor function. This supports the findings of Duncan et al ${ }^{54}$ who reported $84 \%$ of their participants were independence in personal management six months post stroke irrespective of upper limb function.

\section{LIMITATIONS OF THE STUDY}

The limitation of this study was the exclusion of participants who were suffering from cognitive deficits and who were unable to participate actively in assessments for personal management and upper limb function. This reduced the number of suitable research participants. Other factors such as return of lower limb function and trunk control were not assessed in the current study which could have affected personal management mobility and transfers. The sample did not achieve the required size which also affects the generalisability of the results.

There was no blinding in the study as the researcher completed all the assessments at the five assessment points. The loss to follow up of participants, especially those who had good upper limb motor function recovery may also have biased the results. The reasons why participants did not return for follow up was not investigated in this study.

\section{CONCLUSION}

This study considered the profile of patients with stroke attending a tertiary hospital in Soweto. The participants had a mean age lower than that reported in other South African studies but presented with similar comorbidities and types of stroke. Their mean length of stay was similar to the nine days reported previously ${ }^{2}$. The site of lesion appeared to have a direct influence on recovery of upper limb motor function particularly MCA stroke.

At discharge the recovery of functioning in personal management was related to the severity of the upper limb motor dysfunc- tion. Tasks that required the use of one hand such as eating were not related to upper limb motor function. However, a relationship was found between upper limb motor dysfunction and tasks that required the use of both hands such as bathing, dressing and toileting.

Occupational therapy intervention was shown to be beneficial. It contributed to participant's improved performance in personal management tasks, even when upper limb motor function recovery was still suboptimal and participants were taught compensatory techniques to perform these tasks. Although participants did not achieve independence using these techniques in hospital, two months after discharge between $66 \%-75 \%$ of participants could be scored at independent or at modified independence with extra time, a compensatory technique or an assistive device needed. However. one participant remained dependent in all areas of personal management at this stage. Although a plateau in the recovery of upper limb motor function was seen at month 2 post discharge possibly due to a lack of intensive occupational therapy, most participants had achieved independence in performing personal management tasks.

The findings for this study may assist occupational therapists in acute public hospital settings to determine the prognosis for upper limb motor function and personal management for stroke survivors and plan intervention appropriately to yield the best outcomes early after stroke onset.

\section{REFERENCES}

I. Connor MD, Walker R, Modi G, et al. Burden of stroke in black populations in sub-Saharan Africa. The Lancet Neurology. 2007; 6: 269-278.

https://doi.org/10.1016/SI474-4422(07)70002-9

2. Mudzi W, Stewart A and Musenge E. Case fatality of patients with stroke over a 12-month period post stroke. SAMJ: South African Medical Journal. 2012; 102: 765-767

https://doi.org/I0.7I96/SAMJ.5742

3. Parekh I and Rhoda A. Functional outcomes of stroke patients admitted to a tertiary hospital in the Western Cape, South Africa. South African Journal of Physiotherapy. 2013; 69: 10-14.

https://doi.org/10.4I02/sajp.v69i2.23

4. Bryer A, Connor M, Haug P, et al. South African guideline for management of ischaemic stroke and transient ischaemic attack 20I0: a guideline from the South African Stroke Society (SASS) and the SASS Writing Committee. SAMJ: South African Medical Journal. 2010; 100: 750-778.

https://doi.org/I0. I I I I/j. I747-4949.20 I I.00629.x

5 Cawood J, Visagie $S$ and Mji G. Impact of post-stroke impairments on activities and participation as experienced by stroke survivors in a Western Cape setting. South African Journal of Occupational Therapy. 2016; 46: 10-15. http://dx.doi.org/I0.17/59/2310-3833/2016/v46n2a3

6. Cawood J and Visagie S. Stroke Management and functional outcomes of stroke survivors in an urban Western Cape Province setting. South African Journal of Occupational Therapy. 20I6; 46: 2I-26. http://dx.doi.org/I0.17159/2310-3833/2016/v46n3a5

7 Duncan P, W, Homer R, D, Reker D, M, et al. Adherence to Postacute Rehabilitation Guidelines Is Associated with Functional Recovery in Stroke. 2002; 33: 167-178.

https://doi.org/I0.1161/hs0102.101014

8. Legg $L$ and Langhorne P. Rehabilitation therapy services for stroke patients living at home: systematic review of randomised trials. Lancet. 2004: 352-356.

https://doi.org/I0.1016/S0 I40-6736(04)I5434-2

9. Teasell R, Foley N, Hussein N, et al. Evidence based review of stroke rehabilitation. Exeecutive summary (17th edition). Accessed 15 November 2016.

http://www.ebrsr.com/sites/default/files/documents/executivesummary-srebr_final_I6ed.pdf (20I5).

10. Kwakkel G, Kollen BJ, van der Grond J, et al. Probability of regaining dexterity in the flaccid upper limb impact of severity of paresis and time since onset in acute stroke. Stroke. 2003; 34: 2I8I-2I 86 . https://doi.org/I0.1 I6I/0I.STR.0000087I72.16305.CD

II. Bernhardt J, Thuy MN, Collier JM, et al. Very early versus delayed mobilisation after stroke. The Cochrane Library. 2009. https://doi.org//0.1002//4651858.CD006/87.pub2 
12. Craig LE, Bernhardt J, Langhorne P, et al. Early Mobilization After Stroke. Stroke. 2010; 4I: 2632-2636.

https://www.ahajournals.org/doi/full/I 0. I |6 I/strokeaha. I |4.007434

13. Rohweder G, Ellekjær H, Salvesen $\varnothing$, et al. Functional outcome after common poststroke complications occurring in the first 90 days. Stroke. 20I5; 46: 65-70.

https://doi.org/I0.1 I6I/STROKEAHA. I I4.006667

14. Blennerhassett J and Dite W. Additional task-related practice improves mobility and upper limb function early after stroke: a randomised controlled trial. Australian Journal of Physiotherapy. 2004; 50: 219-224. https://doi.org/I0.10 I6/S0004-95 I4(|4)60 I I I-2

15. Wasserman S, De Villiers L and Bryer A. Community-based care of stroke patients in a rural African setting. SAMJ: South African Medical Journal. 2009; 99: 579-583. http://dx.doi.org//0.7/96/SAMJ.3284

16. Ntamo N, Buso D and Longo-Mbenza B. Factors affecting poor attendance for outpatient physiotherapy by patients discharged from Mthatha general hospital with a stroke. South African Journal of Physiotherapy. 2013; 69: 13-18. http://dx.doi.org/10.4102/sajp.v72il .298

17. Gallagher BA, Hart PM, O'Brien C, et al. Mobility and access to transport issues as experienced by people with vision impairment living in urban and rural Ireland. Disability and Rehabilitation. 20 I ; 33: 979-988. https://doi.org//0.3109/09638288.2010.516786

18. Wegner $L$ and Rhoda $A$. The influence of cultural beliefs on the utilisation of rehabilitation services in a rural South African context: therapists' perspective: original research. African Journal of Disability. 20 I5; 4: I-8. https://dx.doi.org/I0.4 I02\%2Fajod.v4il. I 28

19. Veerbeek JM, Kwakkel G, van Wegen EE, et al. Early prediction of outcome of activities of daily living after stroke a systematic review. Stroke. 20II; 42: |482-1488. https://doi.org/I0.1 I6I/STROKEAHA. I 10.604090

20. Meijer R, Ihnenfeldt DS, de Groot IJ, et al. Prognostic factors for ambulation and activities of daily living in the subacute phase after stroke. A systematic review of the literature. Clinical Rehabilitation. 2003; 17: 119-129.

https://doi.org/I0.I I 1 1\%2F02692 I5503cr585oa

21. Hendricks HT, van Limbeek J, Geurts AC, et al. Motor recovery after stroke: a systematic review of the literature. Archives of Physical Medicine and Rehabilitation. 2002; 83: 1629-1637. https://doi.org/I0.1016/SI474-4422(09)70I50-4

22. de Nap Shelton F and Reding MJ. Effect of lesion location on upper limb motor recovery after stroke. Stroke. 200 I; 32: I07-II 2. https://www.ahajournals.org/doi/full//0.1 I6I/0I.str.32.1.107

23. Pandian S, Arya KN and EWR D. Comparison of Brunnstrom Therapy and Motor Relaearning Programme in Rehabilitation of Poststroke Hemiparetic Hand: A randomised Control Trial. Body Work and Movement Therapies. 2012; 16: 330-337. https://doi.org/I0.1016/j.jbmt.20II.II.002

24 Sabari J, Capasso N. Feld-Glazman R, et al.: Optimizing motor planning and performance in clients with neurological disorders. Chapter 21 in Radomski MV and Latham CAT Occupational Therapy for Physical Dysfunction 7th ed. Philadelphia, USA: Wolters Kluwer Health, 2014: 614-674

25. Heller A, Wade D, Wood VA, et al. Arm function after stroke: measurement and recovery over the first three months. Journal of Neurology, Neurosurgery \& Psychiatry. 1987; 50: 7I4-7I9. https://doi.org/10.1 I36/jnnp.50.6.7/4

26. Jørgensen HS, Nakayama $\mathrm{H}$, Raaschou $\mathrm{HO}$, et al. Outcome and time course of recovery in stroke. Part II: Time course of recovery. The Copenhagen Stroke Study. Archives of Physical Medicine and Rehabilitation. 1995; 76: 406-4I2. https://doi.org/10.1016/S0003-9993(95)80568-0

27. Christiansen C. Ways of living: Self-care strategies for special needs. American Occupational Therapy Association, 2000.

28. Gillen $G$ and Burkhardt A. Stroke Rehabilitation: A Function-Based Approach, St. Louis, Mo., Mosby-Year Book. Inc, 2004.

29. Wilcock A. A theory of the human need for occupation. Journal of Occupational Science. 1993; I: 17-24.

https://www.tandfonline.com/doi/pdf/I0. I080/I442759I.1993.96 86375
30. Kielhofner G. Research in occupational therapy: Methods of inquiry for enhancing practice. FA Davis, 2006.

31. Guarte J and Barrios E. Estimation under purposive sampling. Communications in Statistics—Simulation and Computation ${ }^{\circledR}$. 2006; 35: 277-284.

32. South African Guidelines Excellence (SAGE). Final Report 20I42018. (Accessed 3 September 2018)

https://www.cebhc.co.za/files/20I8/05/SAGE-Full-Report.pdf

33. Fugl-Meyer AR, Ja'asko IL, Olsson S, et al. The Post Stroke Hemiplegic patient. Scandinavian Journal of Rehabilitation Medicine. 1975; 7.

34. Gladstone DJ, Danells CJ and Black SE. The Fugl-Meyer assessment of motor recovery after stroke: a critical review of its measurement properties. Neurorehabilitation and Neural Repair. 2002; 16: 232-240. https://doi.org/I0. I007/978-0-387-79948-3 I806

35. Lin J-H, Hsueh I-P, Sheu C-F, et al. Psychometric properties of the sensory scale of the Fugl-Meyer Assessment in stroke patients. Clinical Rehabilitation. 2004; 18: 391-397. https://doi.org/10.1 191/0269215504cr737oa

36. Hsieh Y-W, Wu C-Y, Lin K-C, et al. Responsiveness and validity of three outcome measures of motor function after stroke rehabilitation. Stroke. 2009; 40: I386-I39I. https://doi.org/I0.1 I6I/STROKEAHA. 108.530584

37. Loubser $\mathrm{HJ}$. The validation of nursing measures for patients with unpredictable outcomes. PhD thesis. Faculty of Health Sciences, University of the Witwatersrand, Johannesburg. (Accessed 20 may 2016)

http://wiredspace.wits.ac.za/bitstream/handle/ I0539//27 I 2/ PhD\%20Thesis\%20Completed\%2030\%20May\%2020I 2. pdf?sequence $=\mathrm{I}$ \&isAllowed $=\mathrm{y}$

38. Loubser HJ, Casteleijn D and Bruce JC. The BETA $®$ nursing measure: Calibrating construct validity with Rasch analyses. Health SA Gesondheid. 2015; 20: 22-32. https://doi.org/I0.1016/j.hsag.2015.02.00 I

39 Shepherd RB, and Carr JH. A motor relearning programme for stroke. Butterworth Heinemann, 1987.

40. Trochim WM and Donnelly JP. Research Methods Knowledge Base. 2006. Cengage Learning Boston.

4I TIBCO $®$ Data Science. Statistica Tibco Software Inc. 2018 Accessed 7 November 2019. http://www.statsoft.com/Products/STATISTICA-Features

42. Lemogoum D, Degaute J-P and Bovet P. Stroke prevention, treatment, and rehabilitation in sub-saharan Africa. American Journal of Preventive Medicine. 2005; 29: 95-101. https://doi.org//0.1016/j.amepre.2005.07.025

43. Cerrato P, Grasso M, Imperiale D, et al. Stroke in young patients: etiopathogenesis and risk factors in different age classes. Cerebrovascular Diseases. 2004; 18: I54-159. https://doi.org/10.1 I59/000079735

44. Ntuli ST, Maimela E, Alberts M, et al. Prevalence and associated risk factors of hypertension amongst adults in a rural community of Limpopo Province, South Africa. African Journal of Primary Health Care \& Family Medicine. 20I5; 7. https://dx.doi.org// 0.4102\%2Fphcfm.v7il.847

45. Petrea RE, Beiser AS, Seshadri S, et al. Gender differences in stroke incidence and poststroke disability in the Framingham heart study. Stroke. 2009; 40: 1032-1037. https://doi.org/I0.1 I6I/STROKEAHA. 08.542894

46. Hasumi T and Jacobsen $\mathrm{KH}$. Hypertension in South African adults: results of a nationwide survey. Journal of Hypertension. 20I2; 30: 2098-2104. https://doi.org//0.1097/HJH.0b0I3e328357c0I8

47. Connor MD, Modi G and Warlow CP. Differences in the nature of stroke in a multi-ethnic urban South African population the Johannesburg Hospital stroke register. Stroke. 2009; 40: 355-362. https:// doi.org/I0.1 I6I/STROKEAHA.108.521609

48. Beal CC. Gender and stroke symptoms: a review of the current literature. Journal of Neuroscience Nursing. 2010; 42: 80-87. http://dx.doi.org/I0.1097\%2FJNN.0b013e318I ce5c70

49. Tilling K, Sterne JA, Rudd AG, et al. A new method for predicting recovery after stroke. Stroke. 200I; 32: 2867-2873. https://www.ahajournals.org/doi/pdf/I0.1 I6I/hs I 201.0994/3

50. Benjamin LA, Bryer A, Emsley HC, et al. HIV infection and stroke: current perspectives and future directions. The Lancet Neurology. 
2012; II: 878-890.

https://doi.org/I0.1016/SI474-4422(I2)70205-3

51. Coupar F, Pollock A, Rowe P, et al. Predictors of upper limb recovery after stroke: a systematic review and meta-analysis. Clinical Rehabilitation. 201 I:26(4):291-313.

https://doi.org/I0.1 I77/02692I55 I |420305

52. Verbeke G. Linear mixed models for longitudinal data. Linear mixed models in practice. Springer, 1997: 63-153.

53. Jette DU, Warren RL and Wirtalla C. The relation between therapy intensity and outcomes of rehabilitation in skilled nursing facilities. Archives of Physical Medicine and Rehabilitation. 2005; 86: 373-379. https://doi.org/10.1016/j.apmr.2004.10.018

54. Duncan PW, Goldstein LB, Matchar D, et al. Measurement of motor recovery after stroke. Outcome assessment and sample size requirements. Stroke. 1992; 23: 1084-1089.

http://citeseerx.ist.psu.edu/viewdoc/download?doi=|0. I. I.89| . I | 09\&rep $=$ rep I \&type $=$ pdf

\section{ROLE OF AUTHORS}

- Z Msengana - postgraduate research project.

- $\quad$ P de Witt - supervisor of research project.

- A Owen - supervisor of research project.

- D Franzsen - conceptualisation of article and statistics.

\section{Corresponding Author}

\section{Z Msengana}

Email: zmsengana@gmail.com 